\title{
Narrativas em Diálogo: A Experiência da Telenovela em Múltiplas Plataformas
}

\author{
Mariane Harumi Murakami \\ Doutoranda do Programa de Pós- \\ Graduação em Meios e Processos \\ Audiovisuais da Universidade de São \\ Paulo (PPGMPA-USP) e Mestre pelo \\ Programa de Pós-Graduação em \\ Ciências da Comunicação (PPGCOM- \\ USP) da mesma instituição. Bolsista \\ Capes. Docente dos cursos de \\ graduação da Universidade Braz \\ Cubas, em Mogi das Cruzes, SP. E-mail: \\ mhmurakami@gmail.com
}

\begin{abstract}
Resumo: Propomos investigar os mecanismos discursivos que relacionam, na era "transmídia", as narrativas-matriz e as narrativas transmidiáticas da telenovela brasileira. Assim, apresentamos a proposta de Long (2007), que traz o conceito de códigos de Barthes para detalhar esse funcionamento discursivo; segundo o autor, as narrativas primárias e as secundárias carregam esses códigos que, na experiência ficcional, relacionam as diferentes narrativas audiovisuais, em movimentos intertextuais e interdiscursivos.
\end{abstract}

Palavras-chave: telenovela; narrativa; transmídia; códigos; ficção; realidade.

Abstract: This paper aims to investigate the discursive mechanisms that relate, in the "transmedia era", the main narratives and the transmedia narratives in Brazilian telenovelas. Thus, we present Long's discussion on the Barthesian concept of hermeneutic codes to detail this discursive functioning; according to the author, the primary narratives and the secondary ones carry these codes that, in the fictional experience, link the different audiovisual narratives, in intertextual and interdiscursive movements.

Keywords: telenovela; narrative; transmedia; codes; fiction; reality.

\section{A modernização da ficção seriada televisiva brasileira}

Desde a primeira telenovela brasileira, Sua vida me pertence (1951), muitas águas se passaram pela história da ficção seriada brasileira. Em seus anos iniciais, destacaram-se os roteiros aos moldes dos desenvolvidos pela cubana Glória Magadan - dramalhões com fórmulas infalíveis que retomavam as características do melodrama, fortemente influenciados pela radionovela: "Masmorras, calabouços, tavernas, hospitais e saídas secretas de castelos mal-assombrados, com personagens estereotipados (...), ambientes exóticos, romances dramáticos de capa e espada e personagens misteriosos (MATTELART, 1998, p. 30).

Essa primeira fase da telenovela é classifica por Hamburger (2005) como uma fase "fantasia", que trazia novelas calcadas predominantemente na ficção com histórias de sheiks, príncipes e contos de fadas. Com a saída de Magadan, as telenovelas passaram a abordar um conteúdo mais "realista" absorvendo representações do cotidiano do Brasil. Segundo Hamburger (2005, p.85), "referências à cultura nacional foram expandindo e se tornaram explícitas com o uso das cores da bandeira, entre outros símbolos nacionais". O grande marco dessa nova fase do gênero é Beto Rockfeller, telenovela de Bráulio Pedroso, exibida entre 1968 e 1969. Segundo Fernandes (1982), a obra é o primeiro arquétipo real da telenovela brasileira, que estabeleceu como modelo para o futuro do gênero o 
seguimento livre da história, com linguagem e expressões coloquiais semelhantes ao nosso modo de falar. Além disso, a trama introduz um novo tipo de herói, próximo ao caráter brasileiro, modificando assim a estrutura dramática da história (MATTELART, 1998).

É possível afirmar que Beto Rockfeller marca uma transição pela qual passa a telenovela, que Xavier (2003) denominou de "modernização da teleficção no Brasil, ocorrida nos anos 1970 e 1980", em que se dá o início de uma construção de um modelo mais realista de telenovelas - no sentido da eliminação de fórmulas antigas dos melodramas de rádio, com a introdução de uma preocupação maior com o naturalismo psicológico e o controle relativo do excesso e do sentimentalismo (Ibid.). Essa postura, de acordo com o autor, aproxima a telenovela à crônica, com personagens menos idealizadas, nova postura moral e novas convenções formais. As telenovelas começam a quebrar a antiga concepção radical segundo a qual "na TV, como todos sabem, só são possíveis o plano americano e o primeiro plano. Todo o resto - planos a distância, planos coletivos, planos panorâmicos - é ineficaz" (DEBRIX: 1989, p.560). Nos anos 2000, a chamada "revolução digital" não deixou incólume essa tradicional narrativa ficcional. Na guerra pela audiência, faz parte também a corrida pelas inovações tecnológicas, exclusividades não só do conteúdo, mas também das técnicas utilizadas.

No entanto, a tecnologia digital não se encerra na qualidade de transmissão e recepção de imagens e sons; o próprio processo de interação do telespectador com o meio televisivo já tem sofrido modificações e, com o uso simultâneo da Internet e do celular, essa relação está, rapidamente, modificando-se. Se no início "conteúdo online" significava apenas a disponibilização de informações, resumos, trechos de capítulos e notícias referentes à trama, na era de convergência as redes televisivas estão desenvolvendo narrativas e conteúdos específicos para a rede digital, para atender os consumidores dispostos a seguir seus programas favoritos através de múltiplos canais de comunicação. Trata-se de narrativas "transmídia", termo criado por Jenkins (2009), que as define como histórias que se desenrolam em múltiplas plataformas de mídia, cada uma delas contribuindo de forma distinta "para nossa compreensão do universo; uma abordagem mais integrada do desenvolvimento de uma franquia do que os modelos baseados em textos originais e produtos acessórios" (Ibidem, p. 384).

De acordo com Bordwell (2009), as narrativas serializadas televisivas constituem o melhor lugar para o desenvolvimento de narrativas transmidiáticas, uma vez que elas oferecem tempo para os telespectadores explorarem e criarem ramificações midiáticas. Assim, as narrativas transmidiáticas consistem em informações e conteúdos complementares à narrativa principal, por meio de narrativas paralelas em mídias diferentes. O intuito é, segundo Jenkins (2009), expandir a narrativa para outras mídias, para que o espectador reúna uma infinidade de pedacinhos que se encaixam e agregam informações sobre aquela história e seus personagens.

Ainda que na televisão norte-americana esse fenômeno tenha se delineado há alguns anos, no Brasil essa experiência foi trazida recentemente às produções ficcionais. Os blogs de personagens constituíram essas primeiras tentativas de criação de conteúdo paralelo às tramas televisivas, ou seja, personagens ficcionais que possuem "diários virtuais" com posts sobre seus cotidianos e reflexões, que o espectador pode acessar a qualquer momento, de qualquer lugar. Com o sucesso desses conteúdos, as tramas passaram a investir cada vez mais nas narrativas transmídia. Além disso, lança-se mão de mídias sociais como o Twitter, tanto para a postagem de conteúdo geral sobre a telenovela, quanto para a criação de conteúdo transmidiático ficcional, com perfis de personagens da trama. No caso dessa rede social, há ainda o fenômeno interessante protagonizado por usuários "não-autorizados", em que os próprios espectadores criam contas para outros personagens, fazendo assim a sua contribuição para a narrativa transmídia. 
Nesse panorama, é possível dizer que a "modernização" da telenovela brasileira, desde o seu surgimento na década de 50, não transforma apenas a forma de fazer telenovela, mas transforma principalmente a experiência do espectador diante do produto ficcional. Ele passa, inicialmente, de uma experiência ficcional bastante distante de sua realidade cotidiana, baseada em um mundo fantasioso, para uma experiência ficcional que pretende parecer cada vez mais "realista", em que os diversos elementos da trama apontam para o seu cotidiano (sem esquecer-se da utilização de mecanismos de representação naturalista). Hoje, na era da convergência, o espectador não abandona a narrativa televisiva, mas tem a oportunidade de buscar (ou não) em outras mídias conteúdos para enriquecer a sua experiência ficcional. E isso instaura, assim, novos a(u)tores no discurso ficcional televisivo brasileiro.

\section{Algumas considerações teóricas}

A telenovela é um produto televisivo comumente conhecido por sua natureza de "obra aberta", no sentido de que seu enredo não é totalmente delimitado antes do primeiro capítulo ir ao ar; esse conceito remete-nos ao conceito de Eco, segundo o qual constitui característica imprescindível de toda obra de arte ser uma "mensagem fundamentalmente ambígua, uma pluralidade de significados que convivem num só significante".(1997, p.22). Para o autor, o sentido de uma obra não é definido a priori, uma vez que se tratam, na realidade, de possibilidades de sentidos, produzidos no ato de leitura, na interação entre as instâncias da comunicação, sendo eles autor, texto e leitor.

Segundo Eco, essa interação faz-se presente desde a origem do texto: "Gerar um texto significa atuar segundo uma estratégia que inclui as previsões dos movimentos do outro" (apud Brandão, 1994). Melhor dizendo, "um texto postula o próprio destinatário como condição indispensável não só da sua própria capacidade comunicativa concreta, como também da própria potencialidade significativa" (Ibidem, p.87). Refletindo sobre as palavras de Eco, é possível dizer que o leitor se institui em duas instâncias: no nível pragmático, o texto está sempre atento em relação ao seu destinatário, mobilizando seu discurso de acordo com o seu interlocutor; e no nível linguístico-semântico, o texto é uma "potencialidade significativa" que se atualiza no ato de leitura, "levado a efeito por um leitor instituído no próprio texto, capaz de reconstruir o universo representado a partir das indicações, pistas, que lhe são fornecidas" (BRANDÃO, 1994, p.88).

Neste artigo, interessa-nos especialmente esse conceito de leitor-modelo (Ibid.) (no caso da telenovela, espectador-modelo) discursivamente construído, ou seja, que se produz no texto, por meio de mecanismos textuais. Privilegiaremos, assim, as estratégias do discurso que possibilitam a produção desse "espectro" de leitor (espectador) que se apresenta no próprio texto. Será que o espectador-modelo dos primeiros períodos da telenovela era, por conta da própria configuração da relação de consumo midiático da televisão, mais passivo que hoje? Será que, na era transmídia, o espectador-modelo construído é mesmo aquele delineado pelos pesquisadores da web 2.0, o "espectador-ativo" (LACALLE, 2010, p.86)? Melhor dizendo, será que houve, de fato, essa "passagem do espectador passivo a protagonista na Rede" (Ibid., p.87), que não somente assiste e acompanha as narrativas, mas também participa dessa narrativa, como construtor de conteúdo?

Por outro lado, não podemos esquecer que, se o texto constrói um leitor-modelo, temos também, segundo o autor, a figura de um autor-modelo que, longe de ser o autor empírico, é uma estratégia interpretativa que surge como um dos polos internos à obra. Assim, o texto constrói-se na interação "entre duas estratégias discursivas e não entre dois sujeitos individuais" (ECO, 2004, p.46). Essa noção é particularmente importante para nossa perspectiva, uma vez que o estatuto do autor nas telenovelas envolve um processo amplo, que não se atém à sua 
${ }^{1} \mathrm{http}: / /$ memoriaglobo.globo.com

${ }^{2}$ http://tititi.globo.com/platb/ revistamodabrasil/ e @revistamodabr. ${ }^{3}$ http://tititi.globo.com/platb/ drixmagazine/ e @drixmagazine.

${ }^{4}$ http://tititi.globo.com/platb/ beatricem/ e @beatricem. ${ }^{5}$ http://tititi.globo.com/platb/ jacquesleclair/ e @JacquesLeclair_. ${ }^{6}$ http://especial.tititi.globo.com/ victorvalentim/ e @victorvalentim_. "escritura", mas estende-se para um modo de produção bastante complexo, que vai do roteiro, produção e pós-produção (aí incluídas as narrativas transmidiáticas), configurando-se como o que é comumente conhecido como obra coletiva, com diversos autores empíricos. Sendo assim, pensamos que o conceito de autormodelo nos permitirá dar conta dessa complexidade, uma vez que, de acordo com essa perspectiva, a configuração da autoria depende de traços discursivos, mas põe em jogo o universo do que está atrás do texto, atrás do destinatário e provavelmente diante do texto e do processo de cooperação - denominado pelo autor de "pacto de leitura".

Entendendo essas questões teóricas, propomos neste artigo investigar, a partir das considerações de Long (2007) sobre os estudos de Barthes (1974), a construção dos mecanismos discursivos que relacionam, na era transmídia, as narrativas-matriz e as narrativas transmidiáticas. Como objeto de investigação, apresentaremos a telenovela TiTiTi (2010): a trama televisiva e suas narrativas secundárias, mais especificamente os conteúdos digitais do site oficial da telenovela.

\section{TiTiTi: a convergência está na moda}

TiTiTi, telenovela de Cassiano Gabus Mendes, foi originalmente exibida pela Rede Globo entre 1985-1986, no horário das 19h; retratando o universo da alta costura, tornou-se um grande sucesso, sendo exibida em mais de 20 países $^{1}$. 0 remake, objeto de análise do artigo, foi veiculado entre 2010-2011 e escrito por Maria Adelaide Amaral, que, em uma espécie de homenagem a Gabus Mendes, mesclou à trama original histórias e personagens de outras obras do autor, tais como Plumas e Paetês, Elas por Elas, Locomotivas e Meu Bem, Meu Mal.

TiTiTi nasceu e se desenvolveu no processo cada vez mais crescente, como já mencionado, de transmidiação da telenovela brasileira; a trama apresentou um rico material narrativo disponibilizado na web, cujo desenvolvimento foi possibilitado especialmente pelo tratamento temático da obra. Muito além do tradicional uso das páginas virtuais para a divulgação de informações sobre a trama, de sinopses de capítulos e de vídeos de trechos exibidos, o site oficial de TiTiTi (www.tititi.globo.com) hospeda páginas que, ao menos à primeira vista, cumprem exatamente o papel de uma narrativa transmidiática, em que "desdobrase através de múltiplas plataformas midiáticas em que cada novo texto faz uma distintiva e valiosa contribuição para o todo" (JENKINS, 2009, p,95).

Sem dúvida, o grande diferencial dos conteúdos transmidiáticos de TiTiTi para as demais novelas veiculadas na época foi a quantidade, a variedade, a sua consonância e participação no enredo da novela. Características que, de fato, facilitam e estimulam ainda mais o consumo de qualquer uma das narrativas - a narrativa matriz (ou primária) e as secundárias.

Assim, deixaremos de lado o conteúdo mais "tradicional" - as informações sobre a trama, sobre os personagens, os resumos de capítulos - e nos ateremos ao conteúdo produzido mais condizente com a noção de narrativa transmidiática de Jenkins (2009), ou seja, as tramas que servem como "extensão" da narrativa principal e como complemento à história-matriz, a telenovela. Dentre eles, destacaremos os sites e twitters das revistas fictícias Moda Brasil ${ }^{2}$ e Drix Magazine ${ }^{3}$ e os blogs e twitters dos personagens Beatrice M/Mabi Spina ${ }^{4}$, Jacques Leclair/ André Spina ${ }^{5}$ e Victor Valentim/Ariclenes Martins ${ }^{6}$.

Esses conteúdos têm a característica que nos interessa na discussão sobre narrativa transmidiática: são conteúdos ficcionais produzidos em plataformas diferentes da televisão, aproveitando-se de formatos e gêneros típicos do ambiente digital. Ou seja, não são apenas transposições de vídeos ou comentários sobre a trama televisiva; são materiais desenvolvidos para que o espectador tenha uma 
${ }^{7}$ Esse questionamento é respondido nos três primeiros episódios da série (Ep. 1 - A ameaça fantasma, Ep.2 - O ataque dos clones e Ep.3 - A vingança de Sith), que cronologicamente foram lançados mais tarde, cerca de 20 anos depois da outra trilogia (Ep.4 - Uma nova esperança, Ep.5 - O império contra-ataca e Ep.6 - O retorno do Jedi). continuidade da experiência ficcional em horário diferente daquele em que a telenovela passa na televisão. As revistas e personagens que só existem na ficção ganham vida na tela do computador, é como se eles existissem de fato fora da narrativa televisiva.

É possível dizer que esses conteúdos cumprem o papel de preencher as lacunas que, em qualquer ficção, seriam deixadas por conta da imaginação do leitor ou do espectador, por meio daquilo que John Keats em 1817 denominou (na Literatura) de "capacidade negativa" (negative capability). Trata-se da arte de construir brechas estratégicas em uma narrativa para evocar um sentido de incerteza, mistério ou dúvida na audiência. Simples referências a pessoas, lugares ou eventos externos à narrativa fornecem pistas à história dos personagens e do mundo em que esta se desenvolve. Isso gera um empoderamento na audiência para que completem os espaços com sua imaginação, deixando-os livres para motivar a curiosidade de completá-los (Long, 2007, p.53).

A abertura para que o leitor possa supor ou imaginar certos fatos sobre a trama é inerente a qualquer obra de fiç̧ão, transmidiática ou não. Afinal, é impossível dizer ou contar tudo em uma história. Como espectadores, imaginamos como teria sido, por exemplo, a vida de Anakin Skywalker antes de se tornar o vilão Darth Vader ${ }^{7}$. É a capacidade negativa que possibilita não só o desenvolvimento de narrativas em outras plataformas, mas também o desenvolvimento do fenômeno das fanfics (ou fan fictions), ou "ficções criadas por fãs", hobby literário (ou cinematográfico) cujo objetivo é escrever histórias baseadas em universos ficcionais - personagens, cenários e acontecimentos - criados por terceiros.

Assim, em TiTiTi o conteúdo transmidiático supre, de certa forma, algumas lacunas deixadas pela narrativa televisiva; por meio dos blogs e dos twitters dos personagens, por exemplo, podemos saber um pouquinho mais sobre sua vida, seu dia a dia, aquilo que provavelmente não é pertinente à trama televisiva, mas enriquece ainda mais a construção do personagem. Os sites das revistas Moda Brasil e Drix Magazine, com colunas, textos, vídeos e fotografias que remetem diretamente a eventos da trama principal, dão ao espectador a oportunidade de vivenciar o mesmo mundo dos personagens que ele acompanha diariamente. As publicações "fictícias" não podem ser compradas nas bancas de jornais, mas as "mesmas" matérias podem ser lidas no ambiente digital. E o que enriquece ainda mais essa experiência é a "capacidade negativa" de TiTiTi, ou seja, a trama principal dá estrategicamente a "deixa" para que o espectador busque as informações em outras plataformas. Vale lembrar que essa busca por parte do espectador deve ser sempre opcional, ou seja, a obra precisa dar conta de diversos tipos de espectadores-modelo: como delimita Scolari (2009), o de primeiro nível (consumidores de textos simples, que não mergulham no universo ficcional); de segundo nível (consumidores de mídias simples, que acompanham frequentemente um determinado produto cultural em apenas uma plataforma e compreendem esse universo ficcional); e de terceiro nível (consumidores transmidiáticos, que processam representações de diferentes mídias e linguagens e reconstroem mais extensamente o mundo ficcional). Portanto, na forma ideal da narrativa transmidiática, "cada meio faz o que faz de melhor (...). Cada acesso à franquia deve ser autônomo (...), cada produto determinado é um ponto de acesso à franquia como um todo. A compreensão obtida por meio de diversas mídias sustenta uma profundidade de experiência que motiva mais consumo" (JENKINS, 2009, p.138).

Dando seguimento, essa capacidade negativa, segundo Long (2007) está ligada a "pistas migratórias" (migratory cues), sinais para outra mídia - os sentidos através dos quais vários caminhos narrativos são marcados por um autor e localizados por um usuário através de padrões de ativação. Embora a "capacidade negativa" não precise levar a nada no momento em que é escrita na história, ela limpa um 
espaço na narrativa para que as pistas sejam plantadas (Idem). Em uma narrativa transmídia, essas pistas migratórias estabelecem o movimento intertextual das narrativas, fazendo com que o conteúdo produzido nas narrativas secundárias tenham mais relevância e façam mais sentido dentro da franquia. Pois, por mais que, como considera Jenkins (2009), o perfil do público contemporâneo seja cada vez mais ativo, migratório, socialmente conectado, que exige diferentes formas de entretenimento com espaço para contribuir ativamente, é a constante referência a essas outras narrativas (ou a plantação de pistas migratórias na narrativa matriz) que estimula a busca do espectador. Melhor dizendo, ao mostrar os personagens "blogando" ou lendo as matérias publicadas nos sites das revistas, a narrativa matriz não só aponta para a existência dessas narrativas secundárias, mas também confere a sua raison d'etre.

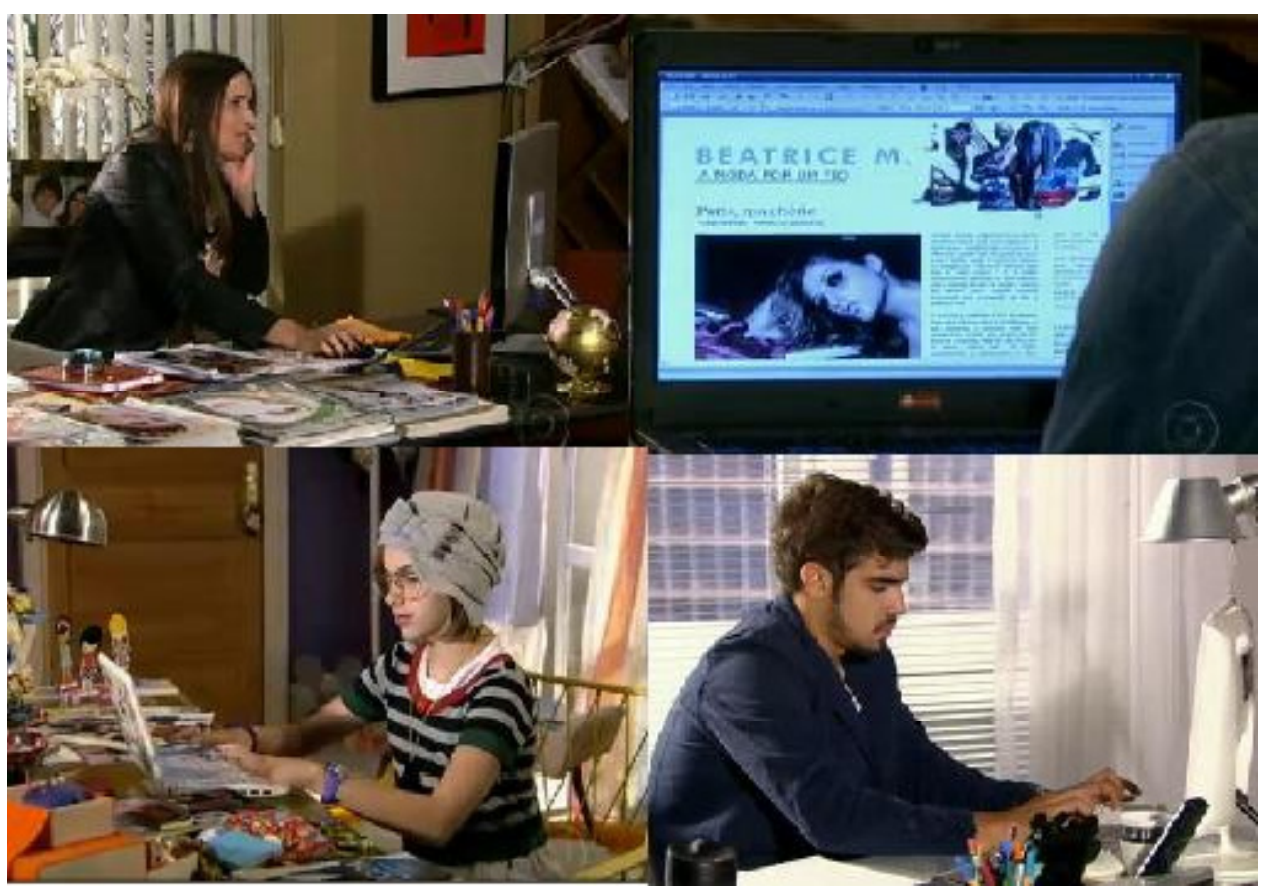

Figura 1 - A plataforma digital na tela televisiva

Na obra em questão, essas pistas migratórias que direcionam o espectador para as mídias digitais permeiam a trama de maneira bastante incisiva ao longo de sua exibição. Citando um texto do próprio site oficial da telenovela, "a web foi uma grande aliada de TiTiTi, quase como se fosse mais um personagem. Foi através da

${ }^{8} \mathrm{http}: / /$ tititi.globo.com/Fique-pordentro/noticia/2011/03/web-foi-umadas-grandes-aliadas-de-ti-ti-ti.html.
${ }^{9} \mathrm{Em} \mathrm{S} / \mathrm{Z}$ (1970), Barthes propõe uma das mais completas teorias dos códigos literários (não definindo literalmente código, mas aproximandose da noção de campo associativo), distinguindo cinco tipos de código para determinar a legibilidade de uma narrativa: código hermenêutico (refere-se à intriga e envolve todos os problemas de interpretação textual), código sêmico (relacionado aos semas que caracterizam as personagens e internet que muitos barracos começaram e muitos segredos foram revelados" ${ }^{\prime}$. Frequentemente o conteúdo transmídia aparecia em cena; diferentes personagens desenvolviam suas ações e diálogos em frente a um computador, seja lendo a última fofoca sobre Victor Valentim na Drix Magazine ou os bastidores da São Paulo Fashion Week na Moda Brasil, seja atualizando o seu blog pessoal.

\section{Decifrando os códigos de TiTiTi}

Long (2007), em sua tese sobre transmedia storytelling, alia aos conceitos de capacidade negativa e pistas migratórias a ideia de códigos de Barthes ${ }^{9}$ para detalhar o funcionamento das narrativas transmídia; segundo o autor, tanto as narrativas primárias (as matrizes) quanto as secundárias (transmídias) carregam em seus discursos esses códigos que, na experiência ficcional, estabelecem relações entre essas narrativas, em movimentos intertextuais e interdiscursivos. Trata-se de uma ideia semelhante à das pistas migratórias, mas Barthes vai além, ao caracterizar o funcionamento de cada um desses códigos, com o objetivo de expor todas as possibilidades de leitura de textos legíveis e textos escrevíveis (Barthes, 1992). 
os cenários em que vivem), código simbólico (que permite a decodificação dos sentidos simbólicos), código proairético (sistema de organização das ações do texto ou estruturação da intriga em sequências) e código cultural (citações de uma ciência ou de uma sabedoria, cultura transmitida). Esses códigos, para o autor, constituiriam a narrativa não como uma linearidade, mas como uma construção intertextual, produto de vários discursos.
Os códigos permitem que a comunicação seja estabelecida em um patamar comum em que o produtor e o receptor de um discurso podem se encontrar. Um código para a leitura de uma narrativa pode ser entendido como um conjunto de regras frouxas em que uma pessoa identifica e interpreta os componentes essenciais de um texto narrativo. Dentre os cinco códigos, destacamos o chamado código hermenêutico, aquele que estrutura o enigma de acordo com a expectativa e desejo para a sua solução. Long desdobra o código hermenêutico em outras seis categorias, que ajudam a entender o funcionamento das pistas migratórias de uma narrativa (transmídia ou não). São eles: códigos hermenêuticos culturais (questões levantadas por pistas que apontam para questões culturais, seja da arte, filosofia, etc.), de personagens (referentes a personagens e pessoas que não aparecem na tela ou possuem participação pequena na narrativa), cronológicos, geográficos, ambientais e ontológicos (os mais raros, aqueles que fazem a audiência questionar sobre a natureza da própria obra).

Os códigos, assim, são categorias potenciais para as pistas migratórias; portanto, esses códigos deixam espaços que podem ser preenchidos, numa narrativa tradicional, pelo próprio espectador ou leitor (modelos). No caso de uma narrativa transmidiática, esses espaços podem ser atualizados ou explicados em textos secundários. Pudemos observar que em TiTiTi (assim como acontece no caso das telenovelas brasileiras em geral), esses códigos e pistas possuem, em alguns casos, funcionamento diferente da narrativa transmidiática norte-americana, por exemplo, Heroes, Lost e Star Wars (para citarmos as mais analisadas nessa questão). Enquanto a estrutura narrativa transmidiática dos programas norteamericanos possui uma formação rizomática, em que a narrativa principal (televisiva) lança mão de códigos hermenêuticos que conduzem a narrativas secundárias construídas em outras plataformas midiáticas, os códigos e pistas de TiTiTi muitas vezes criam uma circularidade narrativa em que há sempre um reforço ao retorno à narrativa matriz.

Para fins comparativos, podemos tomar Heroes como exemplo. Heroes conta a história de indivíduos comuns que desenvolvem super-poderes. O programa se sobressai ao atualizar códigos hermenêutidos de personagens e desenvolvendo histórias secundárias sobre eles. Um dos personagens principais, Mohinder, um professor geneticista indiano, descobre uma importante pesquisa de seu pai, que morreu no início da primeira temporada. Um graphic novel foi criado para clarificar o relacionamento entre o cientista e seu pai, revelando que Mohinder começou a introjetar as crenças científicas de seu pai ainda quando criança. Em um outro exemplo, um graphic novel revela que o avô de Hiro (protagonista da trama) sobreviveu à bomba de Hiroshima, explicando a razão para que Hiro seja tão motivado a salvar o mundo de uma grande explosão. Essas histórias secundárias são questionamentos prováveis que um fã poderia (ou não) pensar perguntar enquanto assiste ao programa, mas que fornecem maior profundidade no mundo de Heroes, especialmente para os fãs mais aficcionados.

Esse tipo de transmidiação pode ser observado no Blog da Stela, página da jornalista da revista Moda Brasil. Trata-se de uma personagem secundária, mas como perfil interessante para o desenvolvimento de conteúdo transmidiático. Em seu blog, Stela mescla posts sobre o mundo da moda, sua carreira e vida pessoal. É interessante observar que, justamente por ser uma personagem secundária, não possui muito destaque na narrativa televisiva, mas a personagem ganha vida e história no ambiente digital. Podemos citar o lançamento de seu livro, que na televisão serviu mais como pano de fundo para o desenvolvimento de ações de personagens principais (Jaqueline e Jacques Leclair), enquanto no blog podemos conhecer detalhes sobre a autora e sobre o livro, que quase não é mencionado na telenovela. É possível ler textos sobre o desenvolvimento do livro, sobre as expectativas da autora e sobre o lançamento, com fotografias e comentários do evento. 
Não podemos esquecer também da vida pessoal dessa personagem; na telenovela, Estela é a mãe de Renato, pai do filho de Marcela, personagem de bastante destaque na trama. Mais uma vez, enquanto na telenovela as relações familiares são tratadas de maneira superficial, no blog temos acesso a diversos pormenores de sua vida com o filho, marido, nora e neto. Ela é também amiga da personagem Jaqueline, uma das protagonistas da trama, a quem dedica vários posts. Assim, o blog preenche vários espaços deixados pela narrativa televisiva em relação à personagem, fazendo com que o espectador se desloque de plataforma midiática. Mas, quase sempre, como já mencionado, faz com que ele se lembre de retornar à narrativa principal, por exemplo, citando eventos e publicando fotos e vídeos da trama televisiva.

Um outro exemplo é a personagem Marcela, que possui uma coluna sentimental dentro do site da Revista Moda Brasil (na trama, a personagem também ganha um espaço na revista fictícia), em que responde e-mails que pedem conselhos amorosos. Na trama televisiva, a coluna não aparece simplesmente como pista direcionando para o conteúdo no ambiente digital, mas a coluna faz parte do próprio enredo da narrativa televisiva. Outras personagens escrevem para a coluna de Marcela pedindo conselhos sobre seus relacionamentos amorosos; Marcela responde e seus conselhos são, de fato, seguidos pelas personagens. As cartas e as respostas aparecem na televisão com os personagens na frente do computador, com a voz em off narrando seu conteúdo, que depois é transcrito para o blog de Marcela em forma de post. Nesse ambiente digital, vemos também cartas e respostas criadas exclusivamente para o esse espaço (ou seja, não são mencionados na narrativa televisiva), aproximando o conteúdo à proposta de transmídia norte-americana discutida anteriormente. No entanto, esse conteúdo insiste em um retorno à narrativa televisiva; é o caso do último post do blog, em que Marcela, ao finalizar seu conselho, escreve: "Mas o tempo conspira a seu favor, e vai te ajudar a enxergar tudo com clareza. Palavra de quem já cruzou esse deserto escuro... E hoje não podia estar mais feliz!". Qual foi esse "deserto escuro" cruzado por Marcela? O que aconteceu na vida amorosa da colunista? Só sabemos se voltarmos à narrativa televisiva.

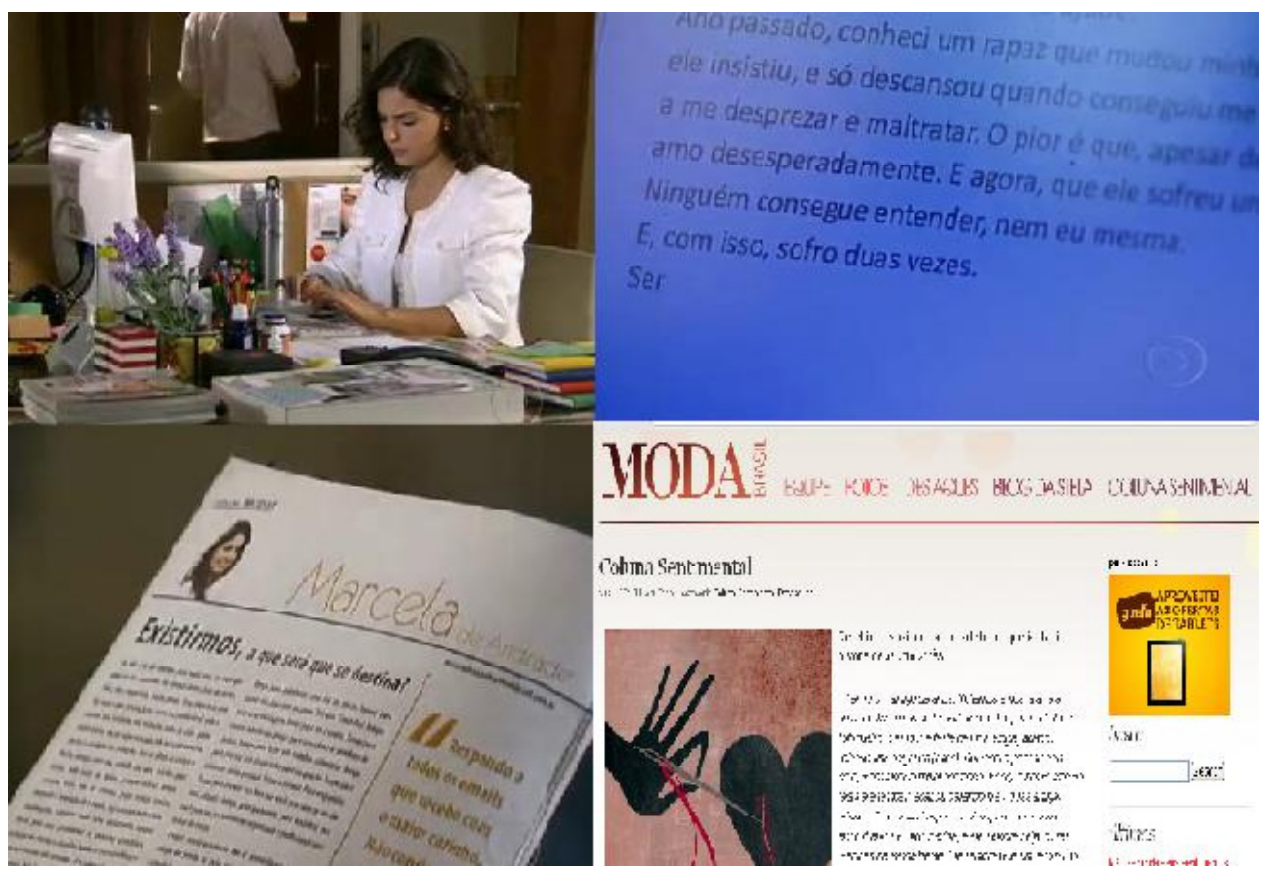

Figura 2 - O blog de Marcela, em múltiplas plataformas.

Os blogs de Jacques Leclair e Victor Valentim, protagonistas da trama, também seguem essa circularidade em relação à narrativa televisiva. Na TV, as páginas virtuais aparecem em rápidas referências dos personagens; geralmente, quando anunciavam alguma novidade. Já os posts dos blogs dos estilistas sempre 
remetem a eventos ocorridos anteriormente na telenovela, ou então a eventos que ocorreram mais tarde, configurando uma espécie de teaser da própria trama para o espectador. Quase sempre, os posts reiteram os eventos ocorridos na trama televisiva: são comentários, na visão dos próprios personagens, sobre os acontecimentos. Não há, estritamente, histórias novas sendo contadas, como ocorre no caso de Heroes

\section{Códigos hermenêuticos, realidade e gêneros discursivos}

Tratando mais especificamente sobre a questão relacionada à classificação dos códigos hermenêuticos desenvolvidos por Long (2007) a partir de Barthes (1974), é possível observar que em TiTiTi esses códigos que remetem a personagens, tempo, espaço e cultura, possuem uma particularidade interessante quando comparadas às narrativas analisadas por Long em sua tese. Na telenovela brasileira, alguns códigos atuavam em referenciações que apontavam para elementos da realidade cotidiana, demandando um espectador-modelo que soubesse reconhecer esses códigos, que podemos chamar de "referenciais".

Logo no primeiro capítulo da trama, na apresentação da temática principal da telenovela, o cenário é a São Paulo Fashion Week, com a participação de diversas personalidades (reais) do mundo da moda. Aqui, temos diferentes códigos hermenêuticos em funcionamento - cultural, geográfico, cronológico (uma vez que o SPFW ocorreu poucas semanas antes do capítulo ir ao ar) e de personagens -, mas que, ao invés de uma interpretação que depende da imaginação do espectador, ativa o conhecimento prévio do espectador, que pode (mas não necessariamente deve) reconhecer aqueles "personagens reais" misturados aos fictícios, criando um jogo entre ficção e realidade. Ademais, os códigos também serviriam para abrir espaço para a criação de narrativas transmidiáticas, uma vez que, citando ainda o caso do evento de moda paulista, o site da Revista Moda Brasil realizou a cobertura dos desfiles, com análises sobre as tendências da época. O mesmo foi feito meses mais tarde, mais próximo ao final da novela, na Rio Fashion Week, em que Marcela e Stela acompanham o evento e realizam análises, na trama televisiva e nas páginas digitais.

O blog de Beatrice M., pseudônimo adotado pela personagem Mabi Spina, também é um exemplo notável de como a telenovela conseguiu ministrar com êxito o desenvolvimento das narrativas transmídia, sem abandonar aquela que, desde os finais dos anos 60, tornou-se a característica que distingue a telenovela brasileira das produções ficcionais de outros países: o afastamento do estilo fortemente melodramático que a caracterizou em seus primórdios, cedendo lugar a temáticas do cotidiano, aproximando ficção e realidade, e combinando convenções formais de diferentes gêneros discursivos (Motter, 2000-2001). A personagem já é, por si própria, um código referencial. Ela estabelece claramente uma relação intertextual com uma figura bastante conhecida no mundo fashion:

${ }^{10} \mathrm{http}: / /$ www.thestylerookie.com/. Tavi Gevinson ${ }^{10}$, uma garota norte-americana de 14 anos que, assim como Mabi, é um precoce gênio da moda, blogueira e fashionista, sem esquecer a inegável semelhança física (e de nome). Esse tipo de intertextualidade visual pode também ser observado nos personagens Ed Silveira e Rony, referências aos excêntricos estilistas Karl Lagerfeld e John Galliano, e Help, paródia da temida editora de moda da Vogue norte-americana Anna Wintour. 

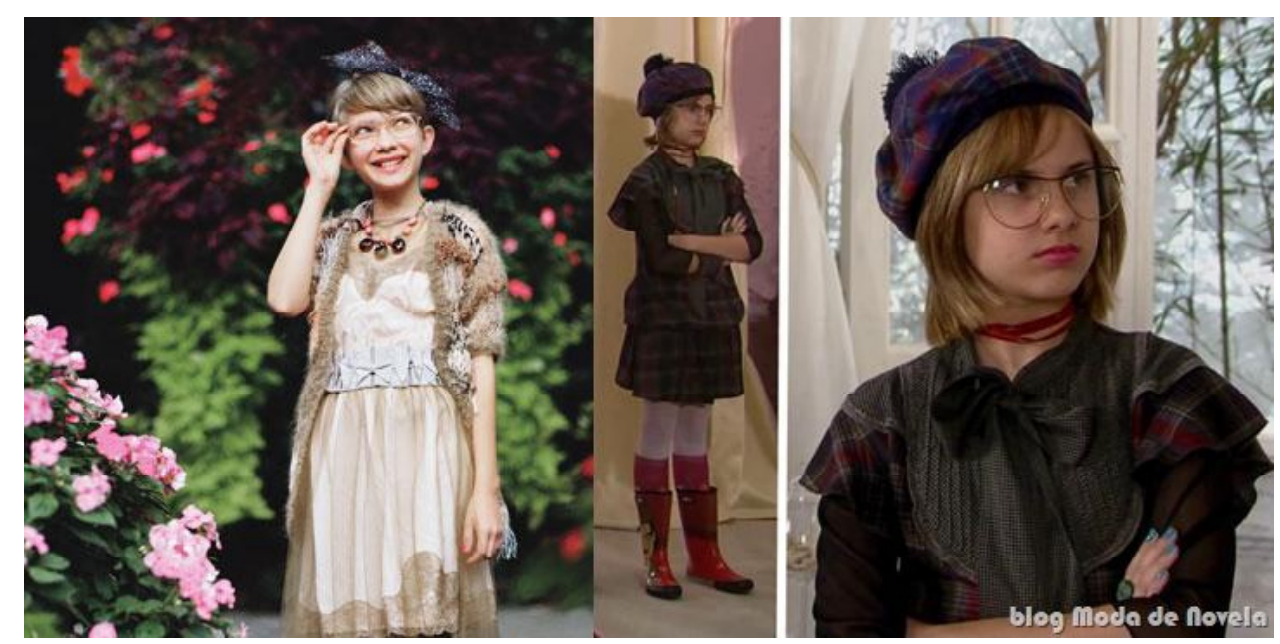

Figura 3 - Tavi Gevinson e Mabi Spina

Sob a identidade de Beatrice M., Mabi escrevia textos que agitavam os núcleos da telenovela. Era uma crítica respeitada (e temida) por todos os estilistas; com um senso apurado para a moda, não perdoou nem seu próprio pai, André Spina/ Jacques Leclair, um "costureiro obscuro da Zona Leste (...) que jamais revelou uma centelha de talento ou originalidade" ${ }^{11}$. Além das críticas de moda, o blog de Beatrice M. também possui posts com coberturas dos desfiles fictícios, fofocas do mundo fashion de TiTiTi, reflexões sobre estilo e entrevistas com personalidades de destaque da moda. Nessas entrevistas, o blog mescla engenhosamente entrevistas fictícias com diversas personagens, tais como a estilista Jaqueline Maldonado e as jornalistas da Revista Moda Brasil Suzana Martins e Stela Sanches, com entrevistas "reais", com figuras reconhecidas no mundo da moda: os jornalistas Maria Prata, Lilian Pacce, Erika Palomino, Mário Mendes, Vivian Whiteman, César Giobbi e Joyce Paskowitch, a consultora Gloria Kalil, a estilista Chiara Gadaleta, a crítica de moda Regina Guerreiro e a figurinista Marília Carneiro (que, aliás, é figurinista de TiTiTi, criando um interessante movimento metatextual). Destacamos ainda as reflexões sobre moda e estilo, em que entram em pauta questões atuais sobre o assunto, como pirataria fashion, consumismo desenfreado, culto ao corpo, moda plus size, supervalorização de produtos importados, entre outros temas incorporados da realidade cotidiana, confirmando a hipótese de diversos estudiosos, como Motter e Jakubazko (2005) e Lopes (2009), de a telenovela brasileira possuir a função de agenda setting $^{12}$, uma vez que tematiza ao espectador de telenovelas questões

${ }^{12} \mathrm{~A}$ tematização é um procedimento informativo que se insere na hipótese do agenda-setting, dela representando uma modalidade particular: tematizar um problema significa, de fato, colocálo na ordem do dia da atuação do público, darlhe o relevo adequado, salientar sua centralidade e o seu significado em relação ao fluxo da informação não-tematizada. (...) a sua função é selecionar posteriormente (...) os grandes temas sobre os quais há que concentrar a atenção do público e mobilizá-la para a tomada de decisões (WOLF, 1995, p.146).

${ }^{13}$ Dentre outros, podemos citar Motter (2000-2001, 2004), Lopes (2002), Souza (2010), Buonanno (1993). relevantes, não só sobre moda, mas também como ela influencia o (bom e mau) comportamento da sociedade.

É possível afirmar que essa referencialidade é ativada também pelo reconhecimento de alguns padrões textuais, de formas e conteúdos possíveis que se repetem socialmente e historicamente. Ou seja, no reconhecimento dos gêneros discursivos. Como já dito, a telenovela brasileira caracteriza-se pelo intrínseco diálogo que estabelece com a realidade; a questão da incorporação dos gêneros de realidade pela narrativa da telenovela vem sendo amplamente discutida pelos estudos de televisão ${ }^{13}$ e eles são responsáveis pela criação de pontos de acesso, na narrativa ficcional, à realidade. Longe de afirmarmos que há a intenção de "enganar" o espectador, queremos dizer que essa apropriação permite a produção de uma leitura documentarizante (Odin, 1984), em especial no que se refere ao seu nível ou estrato realista (Motter, 2004). No entanto, assim como afirma Odin, existem várias possibilidades de leituras documentarizantes, e elas variam de acordo com a obra em questão e especialmente com a posição adotada pelo espectador diante dessa obra: essa leitura pode afetar trechos da obra ou todo o filme, pode ser descontínua ou prolongada, individual ou institucional, interna ou externa, etc. Tratando-se da telenovela, o conhecimento do gênero será um dos pontos fundamentais na produção dessa leitura documentarizante, ou seja, o espectador familiarizado com o funcionamento discursivo da telenovela saberá 
diferenciar o estrato real do estrato melodramático, ainda que muitas vezes as fronteiras sejam bastante sutis.

Dessa forma, é possível distinguir dois tipos de "leitores" da telenovela (Motter, 2003), assim como o fez Umberto Eco: o de primeiro nível, que somente "quer saber (e com razão) como acaba a história" (Eco, 2004, p.33) e "deixa escapar certos detalhes, seja pelo baixo nível de atenção, seja por considerar que à ficção não se deve cobrar rigor de coerência" (Motter, 2003, p. 97); e o de segundo nível, aquele capaz de perceber marcas e pistas deixadas pela instância de enunciação que o leitor de primeiro nível não perceberia. O próprio Odin fala de níveis de leitura: "Quando colocados em evidência os diferentes níveis de leitura, definidos em termos de modalidade de construção do Enunciador, ela se dá conta da diversidade de leituras que podem ser produzidas no quadro da leitura documentarizante" (Odin, 1984, p.275).

Esse fenômeno ocorre também em praticamente todo o conteúdo transmídia analisado; todos os blogs, sites e também os twitters apropriam-se de características "documentais" dos gêneros na produção de narrativas. Aqui, destacamos especialmente os sites das revistas Moda Brasil e Drix Magazine. As duas revistas da ficção têm seus sites configurados aos moldes das revistas "reais" que representam, as revistas de moda e as revistas de fofoca. Ao navegarmos pelas páginas virtuais, apenas as referências a eventos e personagens fictícios indicam que se trata, na realidade, de revistas que não existem nas bancas. Moda Brasil possui reportagens sobre tendências que, de fato, desfilaram pelas passarelas do mundo, além de editoriais de moda com direito a sessões fotográficas criadas especialmente para o conteúdo transmídia e que não devem em nada à Vogue e à Marie Claire. Tudo isso com uma linguagem, cores, fontes e imagens que traduzem a sofisticação e modernidade da publicação. Já Drix Magazine abusa da linguagem sensacionalista típica dos tabloides, com notícias bombásticas e fotografias que simulam flagras de papparazzis. Destacamos os vídeos publicados no site, que seguem estéticas de diversos "gêneros de realidade": as entrevistas jornalísticas com Stéphany, a reportagem sobre o encontro de Stéphany com sua mãe, as videorreportagens sobre Leclair e Valentim, o registro amador (ou caseiro) do casamento de Thaísa. Todo esse material é desenvolvido exclusivamente para as plataformas digitais, com o intuito de reforçar o estatuto do "registro documental" da ficção: a câmera trêmula simulando o registro amador, a captação in loco do som, o exercício metalinguístico de mostrar os aparatos do fazer televisivo (câmera, microfone...), entre outros. Além disso, Drix Magazine inseria notícias reais de celebridades, colocadas no espaço chamado de "Internacionais".

\section{O duplo pacto de leitura nas narrativas transmídia}

Como pudemos observar, no processo de transmidiação de sua trama, TiTiTi lança mão de uma estratégia já bastante conhecida pelo público de telenovelas, ou seja, a constante referência à realidade. Acreditamos que isso se deve a uma tentativa de criar uma narrativa que visa atingir diversos padrões de espectadores-modelo. Assim, desenvolve narrativas em plataformas digitais, mas sem fugir a algumas convenções da telenovela brasileira. Além disso, procura não estender demais a narrativa, tomando o cuidado para que as tramas secundárias sempre lembrem o espectador de retornar à trama televisiva. $O$ resultado é que o espectador é ativo, no sentido de que ele pode procurar narrativas em outras plataformas, mas ainda não é produtor de conteúdo, como aconteceu no seriado Lost, por exemplo. É claro que não estamos postulando um espectador passivo, dizemos apenas que a trama não abriu muitas possibilidades para que o público produzisse conteúdo nessas plataformas. Nos blogs e sites, o espaço que seria destinado à participação do espectador - os comentários - estão desativados. Os twitters são o único lugar em que se percebe uma participação mais ativa do espectador, que interage com 
os personagens por meio da rede social; no entanto, o que produz não participa em nenhuma das outras narrativas.

Mesmo assim, esses perfis nas redes sociais, especialmente os de Victor Valentim e Jacques Leclair, são exemplares para entendermos a questão do espectadormodelo. Se por um lado, os códigos referenciais exigem um espectador-modelo que os reconheça, por outro, a trama exige um tipo de espectador que concorde em crer incondicionalmente na ficção e ainda participar dela. Ou seja, que faça parte de um pacto ficcional, que Umberto Eco descreve da seguinte maneira: "O leitor precisa aceitar tacitamente um acordo ficcional, que Coleridge chamou de 'suspensão de descrença'. O leitor tem que saber que o que está sendo narrado é uma história imaginária, mas nem por isso deve pensar que o escritor está contando mentiras" (1997, p.81).

Murray (2003) afirma que, quando adentramos num mundo ficcional, não "suspendemos" simplesmente uma faculdade crítica, mas exercemos ainda uma faculdade criativa, ou seja, criamos ativamente uma crença. "Por causa do nosso desejo de vivenciar a imersão, concentramos nossa atenção no mundo que nos envolve e usamos nossa inteligência mais para reforçar do que para questionar a veracidade da experiência" (Ibid., p.111). Por outro lado, cremos que o pacto ficcional não seja algo puramente pragmático, mas também um mecanismo discursivo, ou seja, em que o próprio discurso traz em sua própria constituição as "cláusulas" desse contrato. Tal concepção pode ser aproximada à perspectiva defendida por Xavier (2004), segundo a qual o cinema desenvolveu estratégias narrativas que acabaram por oferecer um discurso transparente, naturalizado, por meio de uma capacidade de ocultar seu procedimento de realização ao espectador. No entanto, não há, segundo o autor, uma linearidade que vai da "impressão de realidade" à fé do espectador; existe, de fato, uma interação entre a disposição do espectador e o ilusionismo construído - principalmente por mecanismos discursivos de identificação. Assim, podemos dizer que existe, nesse caso, uma espécie de regime de identificação contratual.

É esse acordo que faz com que, no twitter, os espectadores interajam com os personagens da mesma maneira que interagem com seus followers reais. Os twitters dos protagonistas, especialmente de Jacques Leclair, mostram atualizações frequentes; o personagem respondeu a quase todas as menções feitas com @JacquesLeclair_na rede social. O personagem recebeu, via twitter, críticas sobre seu caráter, elogios relacionados às criações, felicitações de ano novo e até conselhos amorosos. $\mathrm{E}$, como os tweets sempre correspondiam àquilo que era apresentado na trama, era como se o personagem da TV ganhasse vida e "tuitasse" nas horas vagas com seus seguidores.

Muito ainda poderia ser discutido sobre as fronteiras existentes (ou não-existentes hoje) entre ficção e realidade na telenovela; no entanto, não foi nosso foco o debate sobre o estatuto de ficção ou realidade que esse discurso possui. Nossa percepção é a de que, ao longo dos anos, o discurso da telenovela brasileira passa a ser construído no sentido de instaurar discursivamente a identificação do espectador junto à narrativa, fazendo com que haja um reforço da "realidade" da experiência ficcional. A partir do pacto de ficção, criamos um desejo de imersão, e com foco no mundo ficcional, não o questionamos, mas o reforçamos. No caso dos conteúdos transmídia, pressupomos que se desenvolva uma extensão do pacto ficcional para além da tela e da narrativa televisiva. Dessa forma, antes de desenvolver um estudo de recepção relacionado ao consumo dos conteúdos de telenovela e dos conteúdos transmídia envolvidos, propomos que esse processo de identificação e extensão/reforço da experiência ficcional constrói-se discursivamente, através de mecanismos de produção de sentido. Melhor dizendo, que é possível identificar no próprio discurso da telenovela mecanismos discursivos que operam na chave da opacidade/transparência, tentando ocultar os mecanismos de realização, 
não só na telenovela, como nas narrativas existentes em outras mídias - todas com o intuito de criar uma experiência de "imersão" na realidade ficcional. Esses mecanismos estariam presentes do funcionamento interno da narrativa da telenovela (como produto primário), nos produtos transmídia (secundários), assim como na relação dialógica que essas duas instâncias estabelecem - afinal, esses discursos têm que dar conta dos diferentes "espectadores-modelo".

Sobre os códigos hermenêuticos, postulamos que esses códigos internos funcionariam, discursivamente, como cláusulas de um duplo contrato - o factual, de um lado, e o ficcional, por outro - produzindo forças ao mesmo tempo centrípetas (por exemplo, quando a trama faz inserções "documentais", apontando para uma realidade exterior à ficcional) e centrífugas (quando reforçam a imersão no mundo ficcional). Consideramos que esse duplo contrato foi se transformando ao longo da história da telenovela, e na era da convergência, ele insere novas cláusulas: a trama principal (televisiva) mantém esse duplo contrato interno e, ademais, aponta para um conteúdo que é exterior à mídia televisiva, enquanto esse conteúdo transmídia insiste em um retorno à matriz (afinal, eles existem para alimentar o consumo da primeira).

\section{Referências Bibliográficas}

BARTHES, R. S/Z. Rio de Janeiro: Nova Fronteira, 1992.

BORDWELL, D. Now leaving from platform 1. David Bordwell's website on cinema. Publicado em 19 ago. 2009. Disponível em: <http://www.davidbordwell.net/blog/ ? $p=5264>$. Acesso em 26 ago. 2010.

BRANDÃO, H.N. O leitor: co-enunciador do texto. Revista Polifonia. n.1, Cuiabá: Editora da UFMT, 1994, pp. 85-90.

DEBRIX, J. R. O efeito de la TV sobre la estética cinematográfica. In: ROMAGUERA I RAMIÓ, J. y ALSINA THEVENET, H.: Textos y manifiestos del cine.. Madrid: Catedra, 1989.

ECO, U. Seis passeios pelos bosques da ficção. 8. ed. São Paulo: Companhia das Letras, 2004.

. A obra aberta. São Paulo: Perspectiva, 1997.

FERNANDES, I. Memória da telenovela brasileira. São Paulo, Brasiliense, 1982.

HAMBURGUER, E.I. O Brasil antenado: a sociedade da novela. Rio de Janeiro: Zahar, 2005.

JENKINS, H. Cultura da convergência. São Paulo: Aleph, 2009.

LACALLE, C. As novas narrativas de televisão e a internet. Revista MATRIZes. v.3, n.2, São Paulo: 2010

LIPOVETSKY, G. O império do efêmero: a moda e seu destino nas sociedades modernas. São Paulo: Companhia das Letras, 2002

LONG, G. Transmedia Storytelling: Business, Aesthetics and Production at the Jim Henson Company. (Master's dissertation, Comparative Media Studies, MIT, 2007). Disponível em: <http://cms.mit.edu/research/theses/GeoffreyLong2007.pdf>. Acesso em: 10 ago. 2010. 
MATTELLART, A. e MATTELART. M. O carnaval das imagens: a ficção na TV. 2.ed. São Paulo: Brasiliense, 1998.

MOTTER, M. L Mecanismos de renovação do gênero telenovela Empréstimos e doações. In: LOPES, M.I.V.(Org) Telenovela internacionalização e interculturalidade. São Paulo: Loyola, 2004.

Fiç̧ão e realidade: a construção do cotidiano na telenovela. São Paulo: Alexa Cultural, 2003.

A telenovela: documento histórico e lugar de memória. Revista USP, São Paulo, n.48, p.74-87, dez/fev 2000-2001.

MURRAY, J. Hamlet no Holodeck: o futuro da narrativa no ciberespaço. São Paulo: Unesp, 2003.

ODIN, R. Film documentaire, Lecture documentarisante. In: ODIN, R e LYANT, J. C. (ed.): Cinémas et réalites. Saint-Etienne: Universidade de Saint-Etienne, 1984, p. 263-277.

SCOLARI, C. Transmedia storytelling: implicit consumers, narrative worlds andbranding in contemporary media production. In: International Journal of Communication ,v. 3, 2009, p. 586-606.

XAVIER, I. Discurso cinematográfico: a opacidade e a transparência. Rio de Janeiro: Paz e Terra, 2004.

Do senso moral religioso ao senso comum pós-freudiano: imagens da história nacional na teleficção brasileira. In: $O$ olhar e a cena: melodrama, Hollywood, cinema novo, Nelson Rodrigues. São Paulo: Cosac \& Naify, 2003.

WOLF, M. Teorias da Comunicação. Lisboa: Editorial Presença, 1995. 